\title{
PROCEDURAL DISCRETION OF THE COURT WHEN REFUSING TO INITIATE CRIMINAL PROCEEDINGS
}

\author{
Ekaterina S. Azarova \\ Volgograd State University, Volgograd, Russian Federation
}

\begin{abstract}
Introduction: if we consider the content of procedural discretion of the court when refusing to initiate criminal cases, refusing petitions at the stage of preliminary investigation, these refusals are known to be able to be appealed in the district (federal) court (Part 5 of Article 144, Article 122, 125 of the Code of Criminal Procedure of the Russian Federation). In these cases, the judicial review raises a question not only for the defense, but also for the court itself, which is what the actions and decisions of the preliminary investigation bodies in such refusals are and whether there are signs of tort in their actions when making such decisions. The author of this paper sets the goal of research, which is to consider the content of procedural discretion of the court in case of refusal to initiate criminal proceedings. Methods: the methodological framework for the research is the dialectical-materialistic method of cognition, which includes the elements of system analysis, and specific scientific methods, such as the logical and legal ones. Results: based on the legal analysis, the content of judicial discretion in case of refusal to initiate criminal proceedings is revealed. The paper raises a question related to the consideration of judicial discretion as a guarantee of the court's activity at the pre-trial stages of the criminal process. Conclusions: it is revealed that the scheme of judicial discretion in the event of a complaint about the refusal to initiate criminal proceedings should be based on the criteria of judicial discretion at the stage of trial.
\end{abstract}

Key words: discretion of the court, initiation of criminal proceedings, criteria of discretion, refusal to initiate.

Citation. Azarova E.S. Procedural Discretion of the Court when Refusing to Initiate Criminal Proceedings. Legal Concept $=$ Pravovaya paradigma, 2020, vol. 19, no. 4, pp. 144-150. (in Russian). DOI: https://doi.org/10.15688/lc.jvolsu.2020.4.19

УДК 343.1

ББК 67.408
Дата поступления статьи: 27.09.2020

Дата принятия статьи: 25.10.2020

\section{ПРОЦЕССУАЛЬНОЕ УСМОТРЕНИЕ СУДА ПРИ ОТКАЗЕ В ВОЗБУЖДЕНИИ УГОЛОВНОГО ДЕЛА}

\section{Екатерина Сергеевна Азарова}

Волгоградский государственный университет, г. Волгоград, Российская Феддерация

Введение: если рассматривать содержание процессуального усмотрения суда при отказах в возбуждении уголовных дел, отказах в ходатайствах на стадии предварительного расследования, то известно, что эти отказы могут быть обжалованы в районном (федеральном) суде (ч. 5 ст. 144, ст. 122, 125 УПК РФ). В этих случаях при судебном рассмотрении возникает вопрос не только для стороны защиты, но и для самого суда, 
который состоит в том, каковы действия и решения органов предварительного расследования при таких отказах и имеются ли признаки деликта в их действиях при принятии таких решений. Автором в данной статье поставлена цель исследования, которая заключается в рассмотрении содержания процессуального усмотрения суда в случае отказа в возбуждении уголовного дела. Методы: методологическую основу исследования составляют диалектико-материалистический метод познания, включающий в себя элементы системного анализа, и частные научные методы, такие как логико-юридический. Результаты: на основании правового анализа раскрывается содержание судебного усмотрения при отказе в возбуждении уголовного дела. Поднимается вопрос, связанный с рассмотрением судебного усмотрения как гарантией деятельности суда на досудебных стадиях уголовного процесса. Выводы: выявлено, что в основе схемы судебного усмотрения в случае жалобы на отказ в возбуждении уголовного дела должны лежать критерии судебного усмотрения на стадии судебного разбирательства.

Ключевые слова: усмотрение суда, возбуждение уголовного дела, критерии усмотрения, отказ в возбуждении.

Цитирование. Азарова Е. С. Процессуальное усмотрение суда при отказе в возбуждении уголовного дела // Legal Concept = Правовая парадигма. -2020. -T. 19, № 4. -C. 144-150. -DOI:https://doi.org/10.15688/lc.jvolsu.2020.4.19

\section{Введение}

Порядок рассмотрения жалоб на отказ в возбуждении уголовного дела, отказ в удовлетворении ходатайства довольно стандартен (ст. 125 УПК РФ). На решение следователя подается жалоба в суд непосредственно или через следователя. После принятия жалобы в свое производство суд в течение пяти суток, но не позднее этого срока, проводит судебное разбирательство по проверке законности и обоснованности действий или бездействий, решений должностного лица или органа предварительного расследования.

В начале судебного разбирательства суд (единолично) в составе председательствующего объявляет о содержании поступившей жалобы. Если в суд явился заявитель (жалобщик), его защитник или законный представитель либо представитель, а также если в разбирательстве участвует прокурор или следователь либо руководитель следственного органа, то суд обязан разъяснить участвующим и явившимся лицам их права и обязанности в процессе судебного заседания [2; 10]. Судебное разбирательство проводится в форме и по правилам состязательного процесса. Первым представляет и обосновывает жалобу заявитель или лица его представляющие, после чего заслушиваются лица стороны, в отношении которой подана жалоба, при этом только заявитель обладает правом последней реплики.

В случае положительного решения дела для заявителя суд выносит постановление о признании действия или бездействия либо ре- шения соответствующего должностного лица незаконным или необоснованным и устанавливает обязанность устранить допущенное нарушение.

Отраженная в УПК РФ схема судебного разбирательства по жалобе в отказе в возбуждении уголовного дела является упрощенной по форме, так как весь порядок непосредственного ведения судебного заседания и принятия решения отнесен к усмотрению единоличного состава суда. Данная схема распространена на все категории жалоб, поданных в суд на стадиях возбуждения уголовного дела и предварительного расследования.

На стадии возбуждения уголовного дела суд рассматривает варианты жалоб на отказы органов предварительного расследования в возбуждении уголовного дела, при этом надо учитывать, что в данных случаях суд является последней инстанцией предупреждения деликта по соблюдению гарантий и принципов российского уголовного процесса.

Один из самых интересных элементов судебного заседания - это вопрос прав и обязанностей лиц, явившихся на судебное разбирательство по жалобе на отказ в возбуждении уголовного дела. При разъяснении этих прав и обязанностей возникает аналогия с порядком проведения судебного заседания по правилам гражданского судопроизводства [8, с. 18]. По этим правилам истцом выступает гражданин (заявитель), который, по его мнению, является пострадавшим от противоправного деяния, а ответчиком - государственный орган. Здесь возникает парадокс, заключаю- 
щийся в том, что в публичном праве появляются институты частного права, не оговоренные в законе.

\section{Судебное разбирательство на стадии возбуждения уголовного дела}

Рассмотрим эти проблематичные моменты проведения судебного разбирательства на стадии возбуждения уголовного дела. Как уже отмечалось, суд разъясняет права и обязанности участникам процесса. Со стороны истца к ним относится заявитель, он же пострадавший или его законный представитель, а также адвокат как представитель заявителя или пострадавшего. Одним из оснований судебного усмотрения является аналогия закона и аналогия права, что позволяет суду использовать соответствующие нормы УПК РФ [9, с. 68]. При разъяснении прав и обязанностей заявителю или пострадавшему, а в необходимых случаях законному представителю, суд использует аналогии ст. 268 (по отношению к потерпевшему) и ст. 42 (по отношению к потерпевшему) УПК РФ.

Согласно усмотрению суда, в соответствии с аналогией закона к правам заявителя в судебном заседании относится следующий перечень прав:

- давать объяснения;

- представлять материалы, по аналогии к доказательствам;

- заявлять ходатайства и отводы;

- иметь представителя (ч. 10 ст. 42 УПК РФ);

- выступать в судебных прениях (подтверждение аналогии закона - это право заключительной реплики заявителя);

- поддерживать (по аналогии) исковое требование;

- знакомиться с протоколом судебного заседания и подавать на него замечания;

- обжаловать постановление суда;

- приносить жалобы на решения суда;

- осуществлять иные полномочия, предусмотренные УПК РФ.

Главный вопрос, который возникает при аналогии ч. 4 ст. 125 и ст. 37 УПК РФ, о праве представления каких материалов - доказательств здесь может идти речь. Здесь, по нашему мнению, скорее всего, суд должен ис- пользовать по своему усмотрению аналогию права, то есть гл. 6 ГПК РФ.

Согласно аналогии права в качестве ответчика на жалобу в отказе в возбуждении уголовного дела могут выступать прокурор, следователь, руководитель следственного органа, а также иные лица, чьи интересы непосредственно затрагиваются обжалуемым решением $[1$, с. 6]. Что касается прав вышеперечисленных лиц, то согласно п. 8 ч. 2 ст. 37 УПК РФ прокурор вправе участвовать в судебных заседаниях при рассмотрении жалоб в порядке применения ст. 125 УПК РФ, при этом о правах следователя и руководителя следственного органа закон в данной части умалчивает, также как и об обязанностях данных лиц в судебном заседании при рассмотрении жалоб об отказе в возбуждении уголовного дела [3, с. 169]. К иным лицам со стороны ответчика, по нашему мнению, можно отнести проверяемых лиц, которые по аналогии закона могут обладать правами и обязанностями подсудимого (ст. 267) и обвиняемого (cт. 47). К этой категории лиц также можно отнести законного представителя и представителя проверяемого лица.

К правам проверяемого лица, который по аналогии выступает в качестве подсудимого (обвиняемого), суд может отнести обладание правом:

- принимать состав «обвинения», как основание жалобы и возражать против нее;

- давать объяснения по поводу жалобы пострадавшего;

- представлять материалы доказательства;

- заявлять ходатайства и отводы суду;

- участвовать в проведении следственных действий и судебной экспертизы как проверяемое лицо, до возбуждения уголовного дела;

- приносить жалобы на решения суда и участвовать в их рассмотрении;

- знакомиться с протоколом судебного заседания и подавать замечания;

- обжаловать постановление суда и получать копии решений;

- защищать свои права и законные интересы средствами и способами, не запрещенными УПК РФ.

Обязанности проверяемого лица при проведении судебного заседания при рассмотре- 
нии жалобы на отказ в возбуждении уголовного дела в законе не указаны.

К остальным лицам, которые обладают правами и обязанностями свидетелей, аналогия закона, по усмотрению суда, относит очевидцев прошедшего события, которое является предметом судебного разбирательства по жалобе заявителя [6, с. 116]. Данные лица, со стороны истца и ответчика, могут быть вызваны или приглашены в суд, по его усмотрению, в порядке применения аналогии права (ст. 57 ГПК РФ).

Согласно ч. 4 ст. 125 УПК РФ, судебное разбирательство начинается непосредственно с обоснования заявителем своей жалобы по поводу отказа в возбуждении уголовного дела $[5$, с. 10]. Данное обоснование в уголовном процессе проводится по правилам и в соответствии с аналогией ст. 174 ГПК РФ.

$\mathrm{B}$ соответствии с аналогией права, суд по своему усмотрению может затребовать письменные объяснения очевидцев и огласить их в процессе судебного заседания в соответствии с ч. 2 ст. 174 и ст. 166 ГПК РФ [7, с. 95]. Закон не указывает, что должен понимать суд под «обоснованием заявителем своей жалобы», по отказу в возбуждении уголовного дела, поэтому суд, по своему усмотрению, вправе применить аналогию закона апелляционного обжалования.

\section{Содержание жалобы в возбуждении уголовного дела}

По аналогии закона, жалоба в суд первой инстанции по месту отказа в возбуждении уголовного дела должна содержать:

- данные о заявителе;

- указание на отказ и последующие обжалования в отказе в возбуждении уголовного дела;

- доводы заявителя с перечислением оснований отказа, то есть его незаконности и (или) необоснованности;

- перечень прилагаемых материалов, а также подпись заявителя.

Ходатайство о вызове в судебное заседание очевидцев и иных лиц, чьи права и законные интересы нарушены в ходе проведения стадии возбуждения уголовного дела, удовлетворяются по усмотрению суда на основании доводов заявителя.
Обоснование заявителя в суде первой инстанции представляет собой устное изложение претензий и доводов обжалуемого отказа в возбуждении уголовного дела по правилам проведения судебного следствия, с последующими прениями сторон по аналогии с ч. 2 ст. 389 со значком УПК РФ.

Суд, как субъект исследования доказательств в уголовном судопроизводстве, по собственной инициативе истребуя доказательства, обеспечивает выполнение функции правосудия. В том случае, если сторонами представлено недостаточно доказательств для обоснования решения по делу, суд может по своему усмотрению истребовать доказательства. Однако при обжаловании решений следователя, эта функция суда является невостребованной.

Усмотрение суда представляет собой двухконтурную систему, которая включает в себя объективные (судебные) и субъективные (судейские) категории пределов уголовно-процессуального усмотрения по принятию решения, а понятие внутреннего убеждения принципиальное по своей сути объяснение, которое как «норма права» позволяет принимать решения в рамках применения доказательственного права.

Вопрос применения норм процессуального права по усмотрению суда включает в себя и нормы доказательственного права, в том числе и применение внутреннего убеждения судом при оценке доказательств с точки зрения уголовно-процессуального закона. Закрепляя опосредовано в нормативном правовом акте право на усмотрение, законодатель устанавливает юридическое основание для осуществления такой деятельности, так как для усмотрения суда необходим особый режим правового регулирования [4, с. 104]. Следовательно, согласно аналогии закона, способ проверки доводов заявителя аналогичен способу проверки доказательств, представленных по уголовному делу, и по своей сути является прерогативой суда.

По результатам рассмотрения жалобы на отказ в возбуждении уголовного дела суд постановляет оставить жалобу без удовлетворения либо обязать должностное лицо устранить допущенное нарушение (п. 1 ч. 5 ст. 125 УПК РФ). Нарушение должно состоять в не- 
законном действии (бездействии) или необоснованном решении должностного лица органа предварительного расследования. Основанием такого нарушения, по аналогии закона, является:

- несоответствие выводов, изложенных в постановлении об отказе в возбуждении уголовного дела, фактическим обстоятельствам, установленным судом;

- нарушение уголовно-процессуального закона;

- неправильное применение уголовного закона;

- выявление данных и обстоятельств, свидетельствующих о несоблюдении условий порядка рассмотрения сообщений о преступлении, который регламентирован ч. 1 и ч. 3 ст. 144 УПК РФ.

При удовлетворении жалобы заявителя на отказ в возбуждении уголовного дела суд не вправе предрешать вопросы:

1) о наличии в деянии проверяемого лица признаков состава преступления;

2) наличии или отсутствии возможных будущих доказательств по делу;

3) виде и размере ущерба, причиненного пострадавшему.

\section{Выводы}

Учитывая перечисленные пределы усмотрения, суд вправе вынести решение об отмене отказа в возбуждении уголовного дела и проведении дополнительной проверки на срок не более 10 суток с момента вступления постановления суда в законную силу либо обязать соответствующее должностное лицо применить ч. 6 ст. 148 УПК РФ в соответствии с ч. 3 ст. 29 УПК РФ.

Возникает вопрос, возможно ли разрешить вышеперечисленные проблемы, если применять определенную схему судебного усмотрения при разрешении жалоб на отказ в возбуждении уголовного дела и на обжалование ходатайств, поданных стороной защиты в процессе предварительного расследования.

Основой данной схемы судебного усмотрения является гарантия деятельности суда на досудебных стадиях уголовного процесса, где одной из задач суда является предупреждение деликта в отношениях конституционных прав и свобод участников уголовного процесca, а также в препятствовании доступа граждан к правосудию.

Главное условие основы такой схемы это неопределенность процессуальной ситуации, когда суд обязан принять одно из следующих решений:

- удовлетворить жалобу и тем самым нарушить процессуальную самостоятельность следователя и независимость предварительного расследования;

- отказать в удовлетворении жалобы и легитимизировать незаконность действия должностного лица органа предварительного расследования и легализовать принятие им необоснованного процессуального решения.

Один из способов устранения данной проблемы - это перевод ситуации из состояния процессуальной неопределенности в состояние определенного процессуального равноправия сторон. Следовательно, по жалобам на отказ в возбуждении уголовного дела в основе схемы судебного усмотрения находятся критерии усмотрения на стадии судебного разбирательства.

\section{СПИСОК ЛИТЕРАТУРЫ}

1. Азарова, Е. С. Доказательства и доказываниев уголовном судопроизводстве: история, современность и перспективы развития / Е. С. Азарова // Сборник статей по материалам Международной научно-практической конференции, посвященной 95-летию со дня рождения Цили Моисеевны Каз ; редкол.: Ю. В. Францифоров [и др.]. - Саратов, 2020. - С. 5-7.

2. Азарова, Е. С. Понятие «усмотрение суда» в праве / Е. С. Азарова // Правовая парадигма = Legal Concept. - 2019. - T. 18, № 2. - C. 69-73. - DOI: https://doi.org/10.15688/lc.jvolsu.2019.2.10.

3. Азарова, Е. С. Усмотрение суда как часть структуры уголовно-процессуальной парадигмы / Е. С. Азарова // Правовая парадигма = Legal Concept. - 2019. - T. 18, № 4. -C. 166-173. - DOI: https://doi.org/10.15688/lc.jvolsu.2019.4.23.

4. Васильев, Ф. Ю. К вопросу о понятии института отказа в возбуждении уголовного дела в российском уголовном процессе / Ф. Ю. Васильев // Вестник Санкт-Петербургского университета МВД России. - 2015. - № 4 (68). - С. 103-106.

5. Гаврилов, Б. Я. Стадия возбуждения уголовного дела: мнение практиков и ученых / Б. Я. Гаврилов // Вестник Московского университета МВД России. -2016 . - № 4. - С. 7-12. 
6. Гаджиев, Я. А. Основания, условия и последствия отказа в возбуждении уголовного дела / Я. А. Гаджиев // Армия и общество. - 2014. № 6 (43). - С. 112-118.

7. Маслов, А. В. Отказ в возбуждении уголовного дела: правовая природа и проблемы регулирования / А. В. Маслов // Право: история и современность. -2019 . - № 4. - С. 88-96.

8. Семенцов, В. А. О проблеме определения в стадии возбуждения уголовного дела процессуального статуса лица, которому преступлением причинен вред, и возможном пути ее решения / В. А. Семенцов // Общество и право. - 2016. - № 2 (56). - С. 18-27.

9. Шаров, Д. В. Отказ в возбуждении уголовного дела: проблемы правового положения заявителя и пути их решения / Д. В. Шаров // Вестник Московского университета МВД России. - 2015. - №10 . - С. 68-79.

10. Azarova, E. Law Principles as a Means of Limiting Legal Discretion / E. Azarova // IV International Scientific and Practical Conference'Anthropogenic Transformation of Geospace: Nature, Economy, Society'(ATG 2019). - 2020. - P. 26-29.

\section{REFERENCES}

1. Azarova E.S. Dokazatelstva i dokazyvaniye v ugolovnom sudoproizvodstve: istoriya, sovremennost i perspektivy razvitiya [Evidence and proof in criminal proceedings: history, modernity and development prospects]. Frantsiforov Yu.V. et al., eds. Sbornik statey po materialam Mezhdunarodnoy nauchnoprakticheskoy konferentsii, posvyashchennoy 95-letiyu so dnya rozhdeniya Tsili Moiseyevny Kaz [Collection of articles based on the materials of the International Scientific and Practical Conference dedicated to the $95^{\text {th }}$ anniversary of the birth of Tsili Moiseevna Kaz]. Saratov, 2020, pp. 5-7.

2. Azarova E.S. Ponyatiye «usmotreniye suda» v prave [The concept of "discretion of the court" in law]. Pravovaya paradigma $=$ Legal Concept, 2019 , vol. 18, no. 2, pp. 69-73. DOI: https://doi.org/10.15688/ lc.jvolsu.2019.2.10.

3. Azarova E.S. Usmotreniye suda kak chast struktury ugolovno-protsessualnoy paradigmy [Discretion of the court as part of the structure of the criminal procedure paradigm]. Pravovaya paradigma =Legal Concept, 2019, vol. 18, no. 4, pp. 166-173. DOI: https://doi.org/10.15688/lc.jvolsu.2019.4.23.
4. Vasilev F.Yu. K voprosu o ponyatii instituta otkaza $\mathrm{v}$ vozbuzhdenii ugolovnogo dela $\mathrm{v}$ rossiyskom ugolovnom protsesse [On the concept of the institution of refusal to initiate a criminal case in the Russian criminal process]. Vestnik Sankt-Peterburgskogo universiteta MVD Rossii [Bulletin of the St. Petersburg University of the Ministry of Internal Affairs of Russia], 2015, no. 4 (68), pp. 103-106.

5. Gavrilov B.Ya. Stadiya vozbuzhdeniya ugolovnogo dela: mneniye praktikov i uchenykh [The stage of initiation of a criminal case: the opinion of practitioners and scientists]. Vestnik Moskovskogo universiteta MVD Rossii [Bulletin of the Moscow University of the Ministry of Internal Affairs of Russia], 2016, no. 4, pp. 7-12.

6. Gadzhiev Ya.A. Osnovaniya, usloviya i posledstviya otkaza v vozbuzhdenii ugolovnogo dela [Grounds, conditions and consequences of refusal to initiate a criminal case]. Armiya $i$ obshchestvo [Army and Society], 2014, no. 6 (43), pp. 112-118.

7. Maslov A.V. Otkaz v vozbuzhdenii ugolovnogo dela: pravovaya priroda i problemy regulirovaniya [Refusal to initiate a criminal case: the legal nature and problems of regulation]. Pravo: istoriya i sovremennost [Law: history and modernity], 2019, no. 4, pp. 88-96.

8. Semencov V.A. O probleme opredeleniya $v$ stadii vozbuzhdeniya ugolovnogo dela protsessualnogo statusa litsa, kotoromu prestupleniyem prichinen vred, i vozmozhnom puti eye resheniya [On the problem of determining at the stage of initiation of a criminal case the procedural status of a person who has been harmed by a crime, and a possible way of solving it]. Obshchestvo $i$ pravo [Society and Law], 2016, no. 2 (56), pp. 18-27.

9. Sharov D.V. Otkaz v vozbuzhdenii ugolovnogo dela: problemy pravovogo polozheniya zayavitelya $\mathrm{i}$ puti ih resheniya [Refusal to initiate a criminal case: problems of the applicant's legal status and ways to solve them]. Vestnik Moskovskogo universiteta MVD Rossii [Bulletin of the Moscow University of the Ministry of Internal Affairs of Russia], 2015, no. 10, pp. 68-79.

10. Azarova E. Law Principles as a Means of Limiting Legal Discretion. IV International Scientific and Practical Conference'Anthropogenic Transformation of Geospace: Nature, Economy, Society'(ATG 2019), 2020, pp. 26-29. 


\section{ПРОЦЕССУАЛЬНОЕ ПРАВО: ВОПРОСЫ ТЕОРИИ И ПРАВОПРИМЕНЕНИЯ}

\section{Information About the Author}

Ekaterina S. Azarova, Candidate of Sciences (Jurisprudence), Associate Professor, Department of Criminal Procedure and Criminalistics, Volgograd State University, Prosp. Universitetsky, 100, 400062 Volgograd, Russian Federation, aes2404@yandex.ru, https://orcid.org/0000-0001-5130-1653

\section{Информация об авторе}

Екатерина Сергеевна Азарова, кандидат юридических наук, доцент кафедры уголовного процесса и криминалистики, Волгоградский государственный университет, просп. Университетский, 100, 400062 г. Волгоград, Российская Федерация, aes2404@yandex.ru, https://orcid.org/0000-0001-5130-1653 